\title{
Stochastic Fertility, Moral Hazard, and the Design of Pay-As-You-Go Pension Plans
}

\author{
Helmuth Cremer*, Firouz Gahvari ${ }^{\dagger}$ and Pierre Pestieau* \\ *Toulouse School of Economics (IDEI and GREMAQ), 21, allée de Brienne, 31000 \\ Toulouse, France. e-mail: helmuth.cremer@tse-fr.eu \\ 'Department of Economics, University of Illinois at Urbana-Champaign, Urbana, IL 61801, \\ USA. e-mail: fgahvari@uiuc.edu \\ CORE, University of Louvain and CREPP, University of Liège, 7, bd du Rectorat, 4000 \\ Liège, Belgique. e-mail: p.pestieau@ulg.ac.be
}

\begin{abstract}
This article models a two-period overlapping generations economy in the steady state where the realization of the quantity/quality number of children depends on an initial investment in children and on a random shock. It shows that the implementation of the first-best allocation, in which the effort level is publicly observable, requires a subsidy on the investment in children. There should also be full insurance with respect to second-period consumption and pensions must be invariant to the number of children. On the other hand, when investment is unobservable and one cannot subsidize it, the full insurance property goes away. In this case, pensions must be linked positively to the number of children. (JEL codes: $\mathrm{H} 55, \mathrm{~J} 13$ )
\end{abstract}

Keywords: pay-as-you-go social security, stochastic fertility, moral hazard

\section{Introduction}

A number of economists have recently advocated a policy of linking pension benefits (or contributions) to individuals' fertility choices. ${ }^{1}$ The reason for this is that, with a pay-as-you-go (PAYGO) social security system, the higher the number of children, the higher will be the available tax revenues (levied on the children when they grow up) to finance the pensions of the retired population. With all parents sharing the benefits associated with their own and every other parents having more children (the extra tax revenues their action generates), there is a positive externality in the system. This externality, if not corrected, implies that the equilibrium number of children in a decentralized system would be suboptimal.

A second and related issue concerns the 'quality' of children and their human capital accumulation through educational decisions of the parents. The externality here arises because the rate of return of a PAYGO system depends not just on the fertility rate, but also on productivity growth.

1 See, among others, Van Groezen et al. (2000, 2003), Bental (1989), Kolmar (1997), Abio et al. (2004), Fenge and Meier (2005).

(C) The Author 2011. Published by Oxford University Press

on behalf of Ifo Institute for Economic Research, Munich. All rights reserved.

For permissions, please email: journals.permissions@oup.com 
The more productive the children, the higher will be their ability to produce and to pay taxes. This reinforces the public good nature of a family's child-rearing activities. ${ }^{2}$

The counter argument to such a policy is that one does not really know what truly determines fertility, and what accounts for the observed evolution in fertility behavior. In particular, it is clear that no one can fully control fertility. Miscarriage, multiple births and plain infertility imply that the number of children the parents intend to have does not necessarily coincide with the actual number of children they will have. Similarly, one cannot deterministically determine the future earning abilities of children simply by investing in their education and training. Given these realities, linking benefits to the number and/or some measure of the quality of children opens the parents to undesirable and uncontrollable risks.

The underlying problem with such a policy then, at least in case of identical individuals, is one of moral hazard. ${ }^{3}$ The parents' effort level in having and raising productive children is not publicly observable. Nor can it be inferred from the outcome, due to the inherent randomness in the process. Under this circumstance, the pension system provides insurance against the fertility and educational achievements risks. When individuals differ in child-rearing ability, or in the taste for children, the problem will include a dimension of adverse selection as well. The actual number of children will then be determined by effort, child-rearing ability, preferences, and a random component. Again, risk sharing through a PAYGO pension scheme may be desirable.

This article attempts to shed light on these contrasting views. The main question is if one should fully ensure parents against the shocks in fertility and educational attainment of their children by offering everyone the same pension, or if one should link the pensions to the number of children. If the latter is the answer, one would also want to know how.

We posit a model which allows for the externality that different parents impose on one another (through their decisions on how many children to have and how much to invest in them). Now the key distinguishing element between quantity and quality decisions is one of timing. The number of children born is known quite early; the quality of children (i.e. their future earning capacity) is determined much later. To account for both features, one needs a model with at least three periods of decision making. This makes the problem far more complicated than necessary. ${ }^{4}$ We thus do not

On this, see Cigno et al. (2003).

Sinn (2004) has studied this issue in a different setting.

4 Cigno and Luporini (2003) have such a model; however, they do not optimize over tax instruments. 
specifically distinguish between fertility and investment decisions. Instead, we lump the investments in quantity and quality together as if one decision determines both. This simplifies the modeling substantially by allowing us to concentrate on a setting with two periods of decision making (as opposed to three ${ }^{5}$ ). In so doing, we use the concept of number of children in efficiency units that is widely used in growth theory.

We model a two-period overlapping generations economy in the steady state where the realization of the quantity/quality number of children depends on an initial investment in children and on a random shock. Individuals are alike ex-ante. Given the emphasis on quality, we assume that the number of children is observed late in the first period so that the first-period consumption cannot vary with the number of children. The second-period consumption, on the other hand, can be adjusted according to one's number of children. We assume away all financial markets: the only potential mechanisms for transfer of resources to the future in the economy are arrangements between parents and children whereby children help their retired parents with the expectation that their own children would help them, and a PAYGO public pension system. The young divide their income between consumption in the first period and investment in children. To do this, they maximize their expected utility at the beginning of the first period. The old consume their fixed income, plus any additional transfers that they may receive (from their children or the government).

We first characterize the laissez faire equilibrium of this model in the absence of private pension plans, as well as when there exists a within-family pension scheme consisting of direct transfers between the young and their retired parents. Next, we characterize the first-best allocation in which the effort level is publicly observable. We show that under this circumstance, there should be full insurance with respect to secondperiod consumption, and pensions must be invariant to the number of children. We also show that implementation requires a subsidy on the investment in children. On the other hand, when investment is unobservable and one cannot subsidize it, the full insurance property goes away. In this case, pensions must be linked positively to the number of children.

In this article, we have deliberately kept the presentation simple. In a companion paper (Cremer et al. (2006)), we have allowed for private savings and we have assumed that the number of children is observed

5 Three periods are needed to truly account for the distinction between quantity and quality. However, this makes the presentation of the issues more complicated than necessary for the purpose at hand. See, on this, Cremer et al. (2011). 
early in the first period so that the first period consumption could vary with it. Also in this article we assume homogeneity of parents in child rearing and in tastes for children. Introducing heterogeneity matters because it introduces a realistic element of redistribution in the picture, but again it complicates the presentation. ${ }^{6}$

\section{The model}

We model the steady-state of a two-period overlapping generations economy. All individuals are alike ex-ante. They receive an exogenous level of income in both periods of their lives. The second-period income is 'sufficiently smaller' than the first so that the individuals would always want to transfer resources to the future if they can. Preferences depend positively on consumption in the first period, $c$, consumption in the second period, $d$, and the number of children one produces as well as the 'quality' of the children one brings up. The quantity/quality mix of children has two possible realizations: $n_{1}$ or $n_{2}$ with $n_{2}>n_{1}{ }^{7}$ The actual realization of $n_{i}(i=1,2)$ depends on an initial investment in children, $k$, to increase the number of children and to enhance their quality, and on some random shock. Thus, when a parent invests $k$, he will have $n_{2}$ (in terms of quality) children with probability $\pi(k)$ where $0 \leq \pi(k) \leq 1$ and $\pi^{\prime}(k)>0$ $\left(\pi^{\prime \prime}(k)<0\right.$ and $\left.\pi(0)>0\right)$. It is plain that the probability of having $n_{1}$ children is given by $1-\pi(k)$.

The only potential mechanisms for transfer of resources to the future in this economy are a possible arrangement between parents and children whereby children help their retired parents with the expectation that their own children would help them, and a PAYGO public pension system. ${ }^{8}$ The young divide their income, $y$, between consumption in the first period, $c$, and investment in children, $k$. They would do that by maximizing their expected utility at the beginning of the first period. The quality of children are determined at the end of the first period. The old consume $d_{i}$ which is equal to their fixed income, $s$, plus any additional transfers that they may receive. To keep the model simple, assume that preferences over $c, d_{i}$, and $n_{i}$ are represented by an additive utility function. Consequently, at the beginning of the first period, the expected utility of the young

6 On this question see Cremer et al. (2008) See also Gahvari (2009) for a survey on the relation between fertility and pensions stressing the issues of adverse selection and moral hazard.

7 One should think of $n_{i}$ as being measured in 'efficiency units'.

8 In a related paper (Cremer et al. 2006), we consider a storage technology (fixed interest rate) as an alternative channel for old-age provision. 
(i.e. future parents) is written as

$$
U=u(c)+(1-\pi(k))\left[h\left(n_{1}\right)+v\left(d_{1}\right)\right]+\pi(k)\left[h\left(n_{2}\right)+v\left(d_{2}\right)\right],
$$

where $u(\cdot), h(\cdot)$, and $v(\cdot)$ are strictly concave functions. ${ }^{9}$

\subsection{Laissez faire}

In a two-period overlapping generations model, one cannot make binding contracts with one's children to help them at retirement in return for them (i.e. the children) being helped by their own children. Under this circumstance, the only source of consumption when one is old is one's own second-period exogenous income. Consequently, all retired persons, regardless of the number of children they have, will consume the same amount of resources. That is,

$$
d_{1}=d_{2}=s
$$

The young determine their level of investment in children by maximizing

$$
U=u(c)+v(s)+(1-\pi(k)) h\left(n_{1}\right)+\pi(k) h\left(n_{2}\right)
$$

subject to

$$
c+k=y \text {. }
$$

The first-order condition for this problem yields

Proposition 1 Consider the steady state of an overlapping generations economy with no capital and no means of storage. Assume parents can have either $n_{1}$ or $n_{2}$ children $\left(n_{2}>n_{1}\right)$ with probabilities $1-\pi(k)$ and $\pi(k)$, where $k$ denotes investment in children. The laissez-faire allocation is characterized by Equation (2) and

$$
\frac{\pi^{\prime}(k)\left[h\left(n_{2}\right)-h\left(n_{1}\right)\right]}{u^{\prime}(c)}=1 .
$$

9 In this article, we posit that $n$ can either reflect the number of children or the 'quality' of a fixed number of children. Our specification is not suitable to explicitly account for a trade-off between quality and quantity of children. To introduce such a feature, one would have to consider a more specific timing assumption: first, fertility choice and then educational choice, acknowledging that both processes have random elements (see Cigno and Luporini (2003) and Cigno et al. (2003). 
Equation (3) tells us that $k$ is determined in such a way as to equalize the young's expected gain in lifetime utility due to a dollar increase in $k$ (from having more children), with the utility loss due to the one dollar reduction in $c$ (the first-period consumption). Put differently, $k$ is optimal when the young's 'marginal rate of substitution' between $k$ and $c$ is equal to the price of $k$ relative to $c$ (namely, one). Note that the individual cannot smooth his intertemporal consumption by sacrificing $c$ for $d$. However, he will have identical second-period consumption levels across the two states of higher and lower quality of children in both periods.

\subsection{Private transfers between parents and children}

Assume now that we have a within-family pension scheme consisting of direct transfers between the young and their retired parents. ${ }^{10}$ Each individual would, in the steady state, give $T$ dollars to his parent in the first period and receives $T$ dollars from each of his children in the second period. This changes the budget constraint of the first period to

$$
c=y-k-T \text {. }
$$

Similarly, the second period consumption will change to

$$
d_{i}=s+T n_{i} \quad i=1,2 .
$$

Observe that according to (5), more children imply more second-period consumption. Consequently, in the presence of a within-family pension scheme, there would be another reason for wanting to have more children (and thus investing in them).

The young will now maximize (1) subject to the constraints (4) and (5). To characterize the solution in this case, substitute for $c$ and $d_{i}$ from (4) and (5) into (1) and then maximize the resulting equation with respect to $k$ and $T$. Simplifying the first-order conditions, we have

Proposition 2 Consider the steady state of an overlapping generations economy in the presence of a within-family pension plan. The equilibrium allocation is characterized by Equations (4) and (5), and

$$
\begin{gathered}
\frac{\pi^{\prime}(k)\left[h\left(n_{2}\right)+v\left(d_{2}\right)-h\left(n_{1}\right)-v\left(d_{1}\right)\right]}{u^{\prime}(c)}=1, \\
\frac{(1-\pi(k)) n_{1} v^{\prime}\left(d_{1}\right)+\pi(k) n_{2} v^{\prime}\left(d_{2}\right)}{u^{\prime}(c)}=1 .
\end{gathered}
$$

10 This is to serve as a benchmark. We ignore the question of how parents and children agree and adhere to this arrangement. 
Equation (6) is similar to (3) under laissez-faire. As before, it tells us that the optimal level of $k$ equalizes the young's expected gain in lifetime utility due to a dollar increase in $k$, with the utility loss due to the one dollar reduction in $c$. Note, however, that the gain now also includes the difference between $v\left(d_{2}\right)$ and $v\left(d_{1}\right)$. Equation (7) is the optimality condition we attain by allowing for transfer of resources across time through the family pension plan. This tells us that the individual sets $T$ to equalize the expected utility gain in the second-period consumption to the utility loss in the first-period consumption. These equations indicate that the individual optimizes his intertemporal consumption profile, which he can affect through both $T$ and $k$. What the individual cannot do, however, is to smooth his consumption profile across the two states of higher and lower number of children. Specifically, we have $d_{2}>d_{1}$ [see Equation (5)].

\section{First best}

Assume now that the government observes and fully controls all consumption levels so that it can effect a first-best allocation. The government's objective is to maximize the steady-state utility of a representative individual. This corresponds to the maximization of a concave social welfare function defined over the utilities of all present and future generations. ${ }^{11}$

Normalize the total number of the current young, at their given quality type, at one. This implies that we have $1 / \bar{n}(k)$ current old persons (measured in the same efficiency units) where

$$
\bar{n}(k)=(1-\pi(k)) n_{1}+\pi(k) n_{2} .
$$

The aggregate resources of the economy is then equal to

$$
y+\frac{s}{\bar{n}(k)} \text {. }
$$

This should finance the aggregate expenditures in the economy, and we have the following resource constraint:

$$
y+\frac{s}{\bar{n}(k)}=c+k+\frac{1}{\bar{n}(k)}\left[(1-\pi(k)) d_{1}+\pi(k) d_{2}\right] .
$$

The problem of the government is to maximize the steady-state utility (1) subject to the economy's resource constraint. It is summarized by the

11 In our setup, there will be no transitional generations. The move to a new steady state is instantaneous. It will also become clear later that the first-best policy would improve the welfare of the current old generation. 
Lagrangian

$$
\begin{aligned}
\Gamma^{F}= & u(c)+(1-\pi(k))\left[h\left(n_{1}\right)+v\left(d_{1}\right)\right]+\pi(k)\left[h\left(n_{2}\right)+v\left(d_{2}\right)\right] \\
& +\mu\left[\bar{n}(k) y+s-\bar{n}(k)(c+k)-(1-\pi(k)) d_{1}-\pi(k) d_{2}\right] .
\end{aligned}
$$

The optimization is with respect to $c, d_{i}$, and $k$, where $\bar{n}(k)$ is given by (8). The first-order conditions for this problem are:

$$
\begin{gathered}
\frac{\partial \Gamma^{F}}{\partial c}=u^{\prime}(c)-\mu \bar{n}(k)=0, \\
\frac{\partial \Gamma^{F}}{\partial d_{1}}=(1-\pi(k))\left[v^{\prime}\left(d_{1}\right)-\mu\right]=0, \\
\frac{\partial \Gamma^{F}}{\partial d_{2}}=\pi(k)\left[v^{\prime}\left(d_{2}\right)-\mu\right]=0, \\
\left.\frac{\partial \Gamma^{F}}{\partial k}=\pi^{\prime}(k)\left[h\left(n_{2}\right)+v\left(d_{2}\right)-h\left(n_{1}\right)-v\left(d_{1}\right)\right]\right] \\
+\mu\left[(y-c-k)\left(\left(n_{2}-n_{1}\right) \pi^{\prime}(k)-\bar{n}(k)+\left(d_{1}-d_{2}\right) \pi^{\prime}(k)\right] .\right.
\end{gathered}
$$

It immediately follows from Equations (11) to (12) that $d_{1}=d_{2}=d$ so that the first-best outcome entails full insurance. It also follows from these equations and (10) that

$$
\frac{v^{\prime}(d)}{u^{\prime}(c)}=\frac{1}{\bar{n}(k)} .
$$

This corresponds to Equation (7) under the within-family pension scheme. It tells us that $c$ and $d_{i}$ 's are chosen to set the marginal rate of substitution between $d$ and $c$ equal to their relative 'marginal costs'.

Next, substituting $d$ for $d_{1}$ and $d_{2}, u^{\prime}(c)$ for $\mu \bar{n}(k)$ from (10), and $v^{\prime}(d)$ for $\mu$ from (11) or (12), in (13) and rearranging the terms, we have

$$
\frac{\pi^{\prime}(k)\left[h\left(n_{2}\right)-h\left(n_{1}\right)\right]}{u^{\prime}(c)}=1-\frac{\pi^{\prime}(k) v^{\prime}(d)\left(n_{2}-n_{1}\right)(y-c-k)}{u^{\prime}(c)} .
$$

This corresponds to Equation (6) under the within-family pension scheme. As in that equation, the left-hand side of (15) indicates the marginal rate of substitution between $k$ and $c$. The right-hand side reflects the net cost of increasing $k$. The first term (one) is the private cost of $k$ (in terms of $c$ ). The second term indicates the net effect of increasing $k$ on the economy's resources. This is a gain to the society through the positive impact of $k$ on $\bar{n}(k)$. 


\subsection{Decentralization}

Equation (15) indicates that in order to decentralize the first-best allocation, $k$ must be subsidized at the rate of

$$
\tau=\frac{\pi^{\prime}(k) v^{\prime}(d)\left(n_{2}-n_{1}\right)(y-c-k)}{u^{\prime}(c)} .
$$

In addition to $\tau$, first-best implementation requires a tax on the young equal to

$$
T=y-c-k,
$$

and a pension to the old given by

$$
P=d-s .
$$

To see this, consider the economic decision of a young individual facing $T$, $P$, and $\tau$ while choosing $c, k$, and $d_{i}$ to maximize (1). ${ }^{12}$ In so doing, he faces two constraints: the budget constraint when young, $c+(1-\tau) k=y-T$, and the budget constraint when old, $d_{1}=d_{2}=P+s$. His choice of $c$ and $k$ is thus determined through the Lagrangian

$$
\begin{aligned}
\Gamma^{I}= & u(c)+v(s+P)+(1-\pi(k)) h\left(n_{1}\right)+\pi(k) h\left(n_{2}\right) \\
& +\mu[y-T-c-(1-\tau) k] .
\end{aligned}
$$

The first-order conditions of this problem yield precisely the first-best allocation characterized by Equations (10)-(13).

We summarize our results on characterization and implementation of the first-best allocation as

Proposition 3 The first-best allocation is characterized by $d_{1}=d_{2}=d$, $v^{\prime}(d) / u^{\prime}(c)=1 / \bar{n}(k)$, and Equations (9) and (15). It can be 'decentralized' via taxing the young by $T=y-c-(1-\tau) k$, giving all retired people the same PAYGO pension $P=d-s$, and subsidizing $k$ at the rate of ${ }^{13}$

$$
\tau=\pi^{\prime}(k)\left(n_{2}-n_{1}\right) \frac{P}{\bar{n}^{2}(k)} .
$$

That $k$ must be subsidized reflects the positive externality that one's expenditure of $k$ bestows on other people through increasing $\bar{n}(k)$. This is in line with the literature cited above.

Clearly, if there were educational costs proportional to $n_{i}, T$ would be fertility related. Substitute $1 / \bar{n}(k)$ for $v^{\prime}(d) / u^{\prime}(c)$ from (14), $(d-s) / \bar{n}(k)$ for $y-c-k$ from (9), and $P$ for $d-s$, in (16). 


\section{Second best}

The first-best characterization, and the properties of the accompanying PAYGO pension plan, rest on the assumption that the government can control $k$ fully - either directly or through taxation (subsidization in this case). This will be the case if $k$ (and $c$ ) are publicly observable. When the observability assumption is not satisfied, we will be in a second-best environment. Under this circumstance, the full insurance prescriptions of a first-best world may not hold.

To examine this question, assume that $k$ and $c$ are not publicly observable but $n_{i}$ 's are. Policy instruments now consist only of $T$ and $P_{i}$ 's which may vary with one's number of children. First-period consumption continues to be determined by (4) while second-period consumptions is given by

$$
d_{i}=s+P_{i} .
$$

Consider first the young's problem of choosing $k$ when facing the policy instruments $T, P_{1}$, and $P_{2}$. Maximization of (1) subject to (4) and (17), for given $T, P_{1}$, and $P_{2}$, yields the following first-order condition ${ }^{14}$

$$
\frac{\pi^{\prime}(k)\left[h\left(n_{2}\right)+v\left(d_{2}\right)-h\left(n_{1}\right)-v\left(d_{1}\right)\right]}{u^{\prime}(c)}=1 .
$$

Equation (18) is identical to (6) under the within-family pension scheme (although under that scheme, one's choice of $k$ has purely private effects). It replaces (15) under the first best. The left-hand side can again be interpreted as the marginal rate of substitution between $k$ and $c$. However, unlike the first best, this is set equal to one. The choice of $k$ is thus no longer optimal. Indeed, to the extent that $k$ must be subsidized in the first best, one would expect the second-best solution to result in a less than optimal value for $k$. We will show below that this is, in fact, the case.

Let $\widetilde{k}\left(T, d_{1}, d_{2}\right)$ denote the solution to Equation (18), with $c$ and $d_{i}$ 's being given by (4) and (17). This solution describes all possible values of $k$ that the government can induce through its choice of $T, P_{1}$, and $P_{2}$. The following lemma establishes the comparative static properties of $\widetilde{k}\left(T, P_{1}, P_{2}\right)$. They will prove useful in studying the government's problem.

14 The second-order condition is that $\left.\left(d^{2} U / d k^{2}\right)\right|_{k=\tilde{k}}<0$. We prove in the Appendix A that this inequality holds. 
Lemma 1 Let $\tilde{k}\left(T, P_{1}, P_{2}\right)$ denote the solution for $k$ in the problem of maximizing (1) subject to (4) and (17), and $\left.\Delta \equiv\left(d^{2} U / d k^{2}\right)\right|_{k=\tilde{k}}$. We have,

$$
\begin{gathered}
\frac{\partial \tilde{k}}{\partial T}=\frac{u^{\prime \prime}(c)}{(-\Delta)}<0 \\
\frac{\partial \tilde{k}}{\partial P_{1}}=\frac{-\pi^{\prime}(k) v^{\prime}\left(d_{1}\right)}{(-\Delta)}<0 \\
\frac{\partial \tilde{k}}{\partial P_{2}}=\frac{\pi^{\prime}(k) v^{\prime}\left(d_{2}\right)}{(-\Delta)}>0 .
\end{gathered}
$$

The inequality signs are as expected. An increase in first-period taxes reduces net income and with it the young's expenditure on $k$ (as well as $c$ ). An increase in $P_{1}$ reduces the attractiveness of $k$ (puts a lower weight on $\pi(k)$ in the utility function). In consequence, the expenditure on $k$ falls. Finally, an increase in $P_{2}$ will have an exactly opposite effect on $k$ and leads to its going up.

To write the second-best problem, one must restrict the tax instruments to include only $T, P_{1}$, and $P_{2}$ ( $\tau$ is no longer available), and impose the constraint $k=\tilde{k}\left(T, P_{1}, P_{2}\right)$ on the government's problem. With a current young population of one and a current old population of $1 / \bar{n}(k)$, the government's budget constraint is

$$
\bar{n}(k)\left[(1-\pi(k)) T_{1}+\pi(k) T_{2}\right]=(1-\pi(k)) P_{1}+\pi(k) P_{2} .
$$

The second-best problem is then summarized by the Lagrangian

$$
\begin{aligned}
\Gamma^{S} & =u(c)+(1-\pi(k))\left[h\left(n_{1}\right)+v\left(d_{1}\right)\right]+\pi(k)\left[h\left(n_{2}\right)+v\left(d_{2}\right)\right] \\
& +\mu\left[\bar{n}(k) T-(1-\pi(k)) P_{1}-\pi(k) P_{2}\right]+\eta\left[\tilde{k}\left(T, P_{1}, P_{2}\right)-k\right] .
\end{aligned}
$$

The first-order conditions are

$$
\begin{gathered}
\frac{\partial \Gamma^{S}}{\partial T}=-u^{\prime}(c)+\mu \bar{n}(k)+\eta \frac{\partial \tilde{k}}{\partial T}=0, \\
\frac{\partial \Gamma^{S}}{\partial P_{1}}=(1-\pi(k))\left[v^{\prime}\left(d_{1}\right)-\mu\right]+\eta \frac{\partial \tilde{k}}{\partial P_{1}}=0, \\
\frac{\partial \Gamma^{S}}{\partial P_{2}}=\pi(k)\left[v^{\prime}\left(d_{2}\right)-\mu\right]+\eta \frac{\partial \tilde{k}}{\partial P_{2}}=0,
\end{gathered}
$$




$$
\begin{aligned}
\frac{\partial \Gamma^{S}}{\partial k}= & -u^{\prime}(c)+\pi^{\prime}(k)\left\{h\left(n_{2}\right)+v\left(d_{2}\right)-h\left(n_{1}\right)-v\left(d_{1}\right)\right. \\
& \left.+\mu\left[\left(n_{2}-n_{1}\right) T+P_{1}-P_{2}\right]\right\}-\eta=0 .
\end{aligned}
$$

To determine the properties of the second-best solution, we must first determine the sign of $\eta$, the Lagrange multiplier associated with the constraint $k=\widetilde{k}\left(T, P_{1}, P_{2}\right)$. A positive (negative) $\eta$ tells us that the secondbest value of $k$ is less (greater) than its first-best value. Simplifying (26), using the young's first-order condition (18), we have

$$
\eta=\mu \pi^{\prime}(k)\left[\left(n_{2}-n_{1}\right) T+P_{1}-P_{2}\right] .
$$

We show in the Appendix A that $\eta$ is necessarily positive so that the second-best value of $k$ is less than optimal.

We will then also have, from (20) and (24) that $v^{\prime}\left(d_{1}\right)-\mu>0$, and from (21) and (25) that $v^{\prime}\left(d_{2}\right)-\mu<0$. The concavity of $v($.$) then implies d_{2}>d_{1}$ and in consequence $P_{2}>P_{1}$.

We summarize these conclusions as

Proposition 4 The second-best allocation under a PAYGO public pension system implies that the value of $k$ is necessarily less than its first-best value, and that $d_{2}>d_{1}$. Consequently, $P_{2}>P_{1}$ : pensions are linked positively to the number of children.

It is also interesting to observe, from manipulating first-order conditions (23)-(25), that

$$
\frac{(1-\pi(k)) v^{\prime}\left(d_{1}\right)+\pi(k) v^{\prime}\left(d_{2}\right)}{u^{\prime}(c)}=\frac{1-\frac{\eta}{\mu}\left(\frac{\partial \tilde{k}}{\partial P_{1}}+\frac{\partial \tilde{k}}{\partial P_{2}}\right)}{\bar{n}(k)+\frac{\eta}{\mu} \frac{\partial \tilde{k}}{\partial T}} .
$$

Equation (28) corresponds to Equation (7) under the within-family pension scheme and replaces Equation (14) under first best. The lefthand side denotes the marginal rate of substitution between $d_{i}$ and $c$. This was set equal to $1 / \bar{n}(k)$, their relative 'marginal costs', under first best. This will not be the case under second best. Now with $\eta>0$ we have, from (28),

$$
\frac{(1-\pi(k)) v^{\prime}\left(d_{1}\right)+\pi(k) v^{\prime}\left(d_{2}\right)}{u^{\prime}(c)}<\frac{1}{\bar{n}(k)} .
$$

Recall that the above appears as an equality in the first best. 


\section{The traditional PAYGO pension plan}

We now turn our attention to the traditional PAYGO pension plans. Under the traditional system, the pensions of the old are invariant to the number of children. That is, all retired persons receive the same pension $P_{1}=P_{2}=P$ so that there is full insurance with respect to the secondperiod consumption.

The individual's problem yields the 'simplified' (as compared with the second best) first-order condition ${ }^{15}$

$$
\frac{\pi^{\prime}(k)\left[h\left(n_{2}\right)-h\left(n_{1}\right)\right]}{u^{\prime}(c)}=1,
$$

replacing (18). The marginal rate of substitution between $k$ and $c$ is again set equal to one and differs from its optimal level.

To determine the government solution under this system, we must impose the additional restriction $P_{1}=P_{2}$ on our second-best problem. This is summarized by the Lagrangian

$$
\begin{aligned}
\Gamma^{T}= & u(c)+(1-\pi(k))\left[h\left(n_{1}\right)+v\left(d_{1}\right)\right]+\pi(k)\left[h\left(n_{2}\right)+v\left(d_{2}\right)\right]+\mu[\bar{n}(k) T \\
& \left.-(1-\pi(k)) P_{1}-\pi(k) P_{2}\right]+\eta\left[\tilde{k}\left(T, P_{1}, P_{2}\right)-k\right]+\delta\left(P_{1}-P_{2}\right) .
\end{aligned}
$$

The first-order conditions are similar to those under second best. They are not repeated here and instead are given in the Appendix A. Manipulating these conditions yields two interesting properties.

First, as with the second-best solution, $\eta$ is positive here. ${ }^{16}$ This tells us that the resulting value of $k$ under the traditional pension plan is, as with the second best, less than its first best value. Put differently, $k$ is suboptimal whether $P_{1}$ and $P_{2}$ are restricted to be equal or are chosen optimally. If $k$ is observable, we can subsidize it and attain first best. Given that the first-best allocation requires $P_{1}=P_{2}$, imposing this as a restriction will have no impact.

On the other hand, if $k$ is publicly unobservable and cannot be subsidized, the restriction $P_{1}=P_{2}$ is binding. In fact, we show in the Appendix A that $\delta>0$. This means that increasing $P_{2}$ and reducing $P_{1}$ from $P$ is welfare improving. We summarize these results as

Proposition 5 Under the traditional PAYGO public pension system, $k$ is suboptimal. If $k$ is publicly observable, subsidizing it will restore first best. On the other hand, if $k$ is not observable, one can attain the second best by linking pensions positively to the number of children.

\footnotetext{
15 Again, the second-order condition is necessarily satisfied here.

16 The expression for $\eta$ is $\eta=\mu T \pi^{\prime}(k)\left(n_{2}-n_{1}\right)>0$.
} 
As a final observation, note that corresponding to Equation (14) under the first best, we now have

$$
\frac{v^{\prime}(d)}{u^{\prime}(c)}=\frac{1}{\bar{n}(k)+\frac{\eta}{\mu} \frac{\partial \tilde{k}}{\partial T}}>\frac{1}{\bar{n}(k)},
$$

where the inequality sign follows from the fact that $\partial \tilde{k} / \partial T<0$ and $\eta>0$. Comparison with (14) thus suggests that $d$ is also expected to be less than optimal.

\section{Conclusion}

Economists have known for quite sometime now that a PAYGO pension scheme will suffer if fertility rates decline. A series of papers have recently argued that fertility is endogenous with an equilibrium that is suboptimal. The reason for suboptimality is the positive externalities that different sets of parents bestow on one another when each of them decides to have more children. The tax revenues that children generate when they grow up are used to finance the pensions of all retired population. To correct the externality, these papers have advocated a policy of linking pensions positively to the parents' number of children.

The shortcoming of this argument is that fertility cannot be controlled fully. There is always an element of randomness in the number of children that parents actually end up with. Subjecting parents to the risks that they cannot control may very well be undesirable.

This article has shown that if the parents' efforts in having and raising children are publicly observable, a policy of linking pensions to the number of children is misguided. All retired persons should receive the same pensions regardless of their number of children. The corrective policy here is one of subsidizing parents' investment in their children. On the other hand, when investment is unobservable and one cannot subsidize it, the full insurance property goes away. In this case, pensions must be linked positively to the number of children.

\section{Acknowledgements}

This article was presented at the 2003 CESifo Venice Summer Institute workshop 'Taxation and the Family'. We would like to thank the participants and particularly Guy Laroque and Martin Werding for their remarks. We are also grateful to two referees for useful comments. 


\section{References}

Abio, G., G. Mahieu and C. Patxot (2004), "On the Optimality of PAYG Pension Systems in an Endogenous Fertility Setting”, Journal of Pension Economics and Finance 3, 35-62.

Bental, B. (1989), "The Old Age Security Hypothesis and Optimal Population Growth”, Journal of Population Economics 1, 285-301.

Cigno, A. and A. Luporini (2011), “Optimal Policy with Heterogeneous Families, Asymmetric Information and Stochastic Fertility", CESifo Economic Studies 57, 283-304.

Cigno, A., A. Luporini and A. Pettini (2003), "Transfers to Families with Children as a Principal-agent Problem", Journal of Public Economics 87, 1165-1177.

Cremer, H., F. Gahvari and P. Pestieau (2006), "Pensions with Endogenous and Stochastic Fertility", Journal of Public Economics 90, 2303-2321.

Cremer, H., F. Gahvari and P. Pestieau (2008), "Pensions with Heterogeneous Agents and Endogenous Fertility", Journal of Population Economics 21, 961-981.

Cremer, H., F. Gahvari and P. Pestieau (2011), "The Design of Pension Plans with Endogenously Determined Fertility, Education and Ability Types", Journal of Public Economics (forthcoming).

Fenge, R. and V. Meier (2005), "Pensions and Fertility Incentives", Canadian Journal of Economics 38, 28-48.

Gahvari, F. (2009), "Pensions and Fertility: in Search of a Link", International Tax and Public Finance 16, 418-442.

Kolmar, M. (1997), "Intergenerational Redistribution in a Small Open Economy with Endogenous Fertility", Journal of Population Economics 10, 335-356.

Sinn, H.W. (2004), "The Pay-As-You-Go Pension System as Fertility Insurance and an Enforcement Device", Journal of Public Economics 88, 1335-1357.

van Groezen, B., T. Leers and L. Meijdam (2000), "Family Size, Looming Demographic Changes and the Efficiency of Social Security Reform", CentER Working Paper no. 2000-27, Tilburg.

van Groezen, B., T. Leers and L. Meijdam (2003), "Social Security and Endogenous Fertility: Pensions and Child Allowances as Siamese Twins", Journal of Public Economics 87, 233-251. 


\section{Appendix A}

Proof of $\Delta<0$. We have, from the individual's optimization problem under second best,

$$
\begin{gathered}
\frac{\partial U}{\partial k}=-u^{\prime}(c)+\pi^{\prime}(k)\left[h\left(n_{2}\right)+v\left(d_{2}\right)-h\left(n_{1}\right)-v\left(d_{1}\right)\right]=0, \\
\frac{\partial^{2} U}{\partial k^{2}}=u^{\prime \prime}(c)+\pi^{\prime \prime}(k)\left[h\left(n_{2}\right)+v\left(d_{2}\right)-h\left(n_{1}\right)-v\left(d_{1}\right)\right] .
\end{gathered}
$$

Equation (A1) yields the first-order condition given in the text. Substituting from this equation into (A2) and simplifying, we have

$$
\Delta \equiv \frac{\partial^{2} U}{\partial k^{2}}=\pi^{\prime \prime}(k) \frac{u^{\prime}(c)}{\pi^{\prime}(k)}+u^{\prime \prime}(c) .
$$

The concavity of $u($.$) and \pi($.$) imply that the expressions in the right-hand$ side of (A3) are negative.

Proof of $\eta>0$. We have, from (24) to (25),

$$
(1-\pi(k))\left[v^{\prime}\left(d_{1}\right)-\mu\right]=-\eta \frac{\partial \tilde{k}}{\partial P_{1}}, \pi(k)\left[v^{\prime}\left(d_{2}\right)-\mu\right]=-\eta \frac{\partial \tilde{k}}{\partial P_{2}} .
$$

Now assume $\eta<0$. It follows from the above equations and (20)-(21) that $v^{\prime}\left(d_{1}\right)-\mu<0$ and $v^{\prime}\left(d_{2}\right)-\mu>0$ so that $v^{\prime}\left(d_{2}\right)>v^{\prime}\left(d_{1}\right)$ and $d_{2}<d_{1} \Rightarrow P_{2}<P_{1}$. Substituting in (27) then implies $\eta>0$, which is a contradiction.

\section{The traditional PAYGO plan}

(i) First-order conditions are as follows:

$$
\begin{gathered}
\frac{\partial \Gamma^{T}}{\partial T_{1}}=-u^{\prime}(c)+\mu \bar{n}(k)+\eta \frac{\partial \tilde{k}}{\partial T}=0, \\
\frac{\partial \Gamma^{T}}{\partial d_{1}}=(1-\pi(k))\left[v^{\prime}\left(d_{1}\right)-\mu\right]+\eta \frac{\partial \tilde{k}}{\partial d_{1}}+\delta=0, \\
\frac{\partial \Gamma^{T}}{\partial d_{2}}=\pi(k)\left[v^{\prime}\left(d_{2}\right)-\mu\right]+\eta \frac{\partial \tilde{k}}{\partial d_{2}}-\delta=0,
\end{gathered}
$$




$$
\begin{aligned}
\frac{\partial \Gamma^{T}}{\partial k}= & -u^{\prime}(c)+\pi^{\prime}(k)\left\{h\left(n_{2}\right)+v\left(d_{2}\right)-h\left(n_{1}\right)-v\left(d_{1}\right)\right. \\
& \left.+\mu\left[\left(n_{2}-n_{1}\right) T+d_{1}-d_{2}\right]\right\}-\eta=0 .
\end{aligned}
$$

(ii) Proof of $\delta>0$. First, observe that

$$
\frac{\partial \tilde{k}}{\partial d_{1}}+\frac{\partial \tilde{k}}{\partial d_{2}}=0
$$

To prove (A8), just substitute from (20) to (21) while noting $d_{1}=d_{2}$. Second, from (A5) to (A6), we have

$$
\frac{\partial \Gamma^{T}}{\partial P_{1}}+\frac{\partial \Gamma^{T}}{\partial P_{2}}=v^{\prime}(d)-\mu+\eta\left(\frac{\partial \tilde{k}}{\partial P_{1}}+\frac{\partial \tilde{k}}{\partial P_{2}}\right)=0 .
$$

This, via (A8) implies $v^{\prime}(d)=\mu$. Substituting in (A6) yields:

$$
\delta=\eta \frac{\partial \tilde{k}}{\partial P_{2}}>0
$$

